\title{
Vertical electrical resistivity sounding (VERS) of tundra and forest tundra soils of Yamal region**
}

\author{
Ivan Alekseev ${ }^{1}$, Jakub Kostecki ${ }^{2}$, and Evgeny Abakumov ${ }^{1}$ \\ ${ }^{1}$ Department of Applied Ecology, Faculty of Biology, Saint Petersburg State University, 16th line of Vasilyevsky Island 29, \\ 199034 Saint Petersburg, Russia \\ ${ }^{2}$ Institute of Environmental Engineering, Faculty of Civil Engineering, Architecture and Environmental Engineering, \\ University of Zielona Góra, Prof. Z. Szafrana 15, 65-516 Zielona Góra, Poland \\ Received May 26, 2016; accepted January 2, 2017
}

\begin{abstract}
A b s t r a c t. The aim of the study was to determine electrical resistivity peculiarities of tundra and forest tundra soils and soil-permafrost layers of the Yamal region. Measurements of electrical resistivity of soil and permafrost strata were performed with a portable device LandMapper (to a depth of 300-500 cm). These measurements allow determination of the values of apparent electrical resistivity of soils and permafrost at different depths and determination of the depths of the permafrost table on each key plot. It was found that there are several trends in vertical distribution of apparent electrical resistivity values. The first trend is a monotonous increase in electrical resistivity values to the depth. It may be explained by the increasing electrical resistivity within the soil depth in relation to the increase in permafrost density. The second trend is a sharp decrease replaced by a gradual increase in electrical resistivity values caused by changing of non-frozen friable debris to frozen massive crystalline rock. These differences were related to the type of landscape: flat lowlands composed of friable grounds underlain by permafrost or friable grounds with permafrost underlain by a rock crystalline layer.

$\mathrm{K}$ e y w o r d s: electrical resistivity, permafrost table, soils, tundra, forest tundra
\end{abstract}

\section{INTRODUCTION}

Soils play a significant role in functioning and evolution of polar biomes. Studying the soil cover of the Arctic region is an important issue given the insufficient knowledge about the taxonomic and functional diversity of soils and their role in ecosystem functioning. Until recently, polar soils have been considered via the paradigm of bioclimatic properties, while the lithological (or so-called geogenic) peculiarities were underestimated (Goryachkin, 2010).

*Corresponding author e-mail: alekseevivan95@gmail.com **This work was supported by Russian Foundation for basic research, grant 16-34-60010, Russian presidents grant for Young Doctors of Science No. MD-3615.2015.4 and the Government of the Yamalo-Nenets Autonomous District.
Studying the influence of permafrost on soil formation processes is one of the most significant issues for the northern part of Western Siberia, which is in the zone of continuous permafrost (Tarnocai et al., 2009). The active layer thickness and the depth of the permafrost strata are significant features of the soil cover of such an area. However, currently there are no sufficient data about these parameters.

Geophysical approaches have been repeatedly used to study permanently frozen ground and permafrost strata (Abakumov, 2016; Abakumov and Parnikoza, 2015; Scott et al., 1990). It was shown that vertical electrical sounding allows determining the permafrost table depth without mechanical penetration into the soil-permafrost layer (Abakumov and Parnikoza, 2015). This is especially important for permanent monitoring in plots where soils are affected by mechanical disturbance due to regular steel bar penetrating from year to year, and this leads to overestimation of the permafrost degradation process. Another important advantage of vertical electric sounding is the possibility to fix the permafrost table depth during soil mapping without digging numerous soil profiles. The effectiveness of application of vertical electric sounding for investigation of soils in different polar environments was substantiated earlier (Abakumov, 2016). The usability of this methodology for investigation of soil salinization and excess moisture in different environments has also been shown (Pozdnyakov, 2008). The electrical resistivity of soils is a function of a number of soil properties, including soil chemical composition (especially water-soluble salt content), the nature of solid constituents (particle size distribution, mineralogy), porosity, pore size distribution, connectivity, water content,

(C) 2017 Institute of Agrophysics, Polish Academy of Sciences 
and temperature (Magnin et al., 2015; Pozdnyakov, 2008; Samouëlian et al., 2005). A specific relationship between the soil strength and electrical resistivity was shown (Sudha et al., 2008). According to the author, this relationship is probably based on parameters controlling soil strength as well as electrical resistivity (degree of saturation, grain size distribution, porosity, cementation). It was also described in detail that clay content in the soil might change the relationship between the soil strength and electrical resistivity.

A great contribution to the study of soil electrical parameters was made by Pozdnyakov (Pozdnyakov et al., 2006; Pozdnyakov, 2008). The author showed that the manifestations of soil electrical parameters are described by such electrophysical laws as the Maxwell, Poisson, Laplace, and Boltzmann laws. According to the author, these laws can serve as prerequisites for formation of the basis for the theoretical interpretation of the behaviour of soil electrical parameters.

In general, the electrical resistivity of soil and rock materials increases slightly with decreasing temperature. In case of water, the increase is $c a .2 \%$ per $1^{\circ} \mathrm{C}$ decrease (Keller and Frischknecht, 1966). The electrical resistivity increases rapidly at the freezing point due to the phase change from conducting water to non-conductive ice. A 5 to 10 fold inrease in electrical resistivity was reported for sand, gravel, and silt in the case of temperature decreasing from unfrozen conditions to $-5^{\circ} \mathrm{C}$ (Hoekstra and McNeill, 1973; Hoekstra et al., 1975; Olhoeft, 1978; Scott and Kay, 1988). A 2 to 3 fold increase was also observed for clay, clayey till, and peat, as well as a 50 to 100 fold increase for crystalline under the same conditions. The value of electrical resistivity increasing from temperatures above zero to permafrost conditions (ie below $0^{\circ} \mathrm{C}$ ) strongly depends on the chemistry of the pore water. In the case of high content of dissolved salts in the pore water, the water remains partially unfrozen at $0^{\circ} \mathrm{C}$ (even at lower temperatures) and the changes in electrical resistivity values remain smooth and weak (King et al., 1988, Scott et al., 1990).

Water is retained in the soil by electrostatic forces between molecules of different solutes and the solid phase of the soil (Van der Waals forces) and interfacial tension in the capillaries. In the case of low water contents, the forces of molecular attraction are predominant (Iwata et al., 1995; Kemper et al., 1975).

The relationship between the electric resistivity and soil water content are crucial for choosing the conditions of using field electrophysical methods for reclamation and agricultural purposes (Pozdnyakov et al., 2006). Electrical current in soils depends on the amount of water in the pores and on its quality.

Direct current resistivity methods are used not only for identification of permafrost depth and soil profile heterogeneity in the natural environment (Abakumov and Parnikoza, 2015; Hauck and Vonder Mühll, 1999), but also for estimation of soil flooding rates in urban areas and other applied research projects (Smernikov et al., 2008). Such geophysical methods have been widely used for permafrost identification and have many advantages in the context of fieldwork. These methods are relatively cheap and simple. Equipment for such investigations is easy to handle and does not require a lot of hand-labour during the fieldwork.

Studies conducted earlier have shown that the soil cover of the Yamal peninsula is very diverse and expressed at least by four soil zones (arctic desert, tundra zone, arctic steppe, forest-tundra) (Ivanov et al., 2015; Vasilevskaya, 1980). Moreover, the soil cover of the Polar Urals also has not been sufficiently studied. Most of research has been focused on the study of the western macroslope of the Polar Urals (Dymov and Zhangurov, 2011; Dymov et al., 2013). The eastern macroslope of the Polar Urals has not been studied in detail. Similarly, there have been no electrophysical surveys of the soil cover of Yamal and North-West Siberia.

The aim of this study is to determine the depth of the permafrost table and active layer thickness in different landscapes of Yamal tundra and forest tundra with the electrical resistivity method.

The objectives of the investigation were:

1. to apply the vertical electrical soundings (VERS) Schlumberger methodology to investigation of vertical soil-permafrost layer stratification in field conditions,

2. to evaluate the permafrost table depths in selected Gleyic and Cryogenic soils of the Yamal region.

\section{MATERIALS AND METHODS}

This study was focused on investigation of the soils of the southern part of the Yamal region (North-West Siberia, Russia). Data were collected during the complex scientific expedition 'Yamal-2015' in August 2015. The area of study is located in the southern part of the Yamal peninsula and the Polar Urals and includes four key plots (Fig. 1). The mean altitude of the studied area is $95 \mathrm{~m}$ a.s.l.

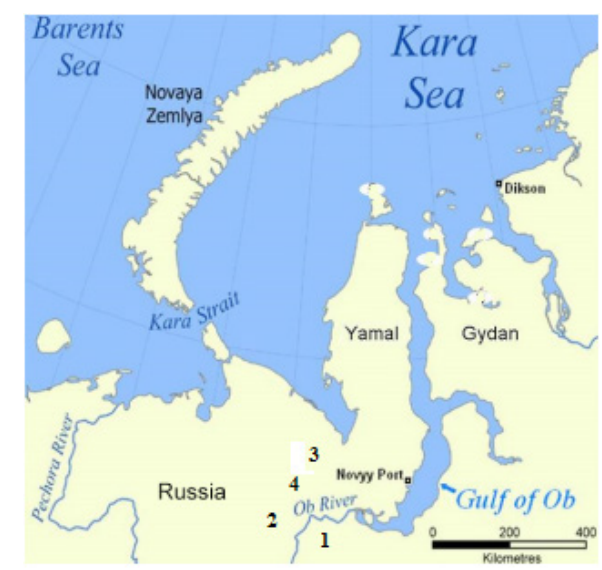

Fig. 1. Area of the study: 1 - surroundings of Salekhard city, 2 - the Polar Urals (mountain Chyornaya), 3 - surroundings of Khalyatalbey river, 4 - foothills of the Polar Urals. 
The southern part of the Yamal peninsula is a relatively flat low accumulative plain. The main features of the relief are the presence of steps and terracing. Terraces are formed mainly by sea abrasion and accumulation (Generalov, 1995). Various forms of micro- and mesorelief, which are dominated by cryogenic forms (polygonal forms of upward and downward movement, thermokarst lakes and depressions, hydrolaccolithes), complicate the surface of the terraces. Formation of the specific relief of the Polar Urals is caused by processes of cryogenic weathering, which result in formation of kurums and patterned grounds. The presence of permafrost and frequent temperature fluctuations leads to development of solifluction processes. The development of solifluction processes contributes to permafrost and frequent temperature fluctuations (Mil'kov and Gvozdecky, 1986).

It must be noticed that the studied area is a transition zone between the forest tundra zone and the tundra zone. In this regard, the vegetation cover is represented by both forest and tundra vegetation

Parent materials are represented mainly by clay and loamy deposits (marine origin), which are underlain by permafrost. In the case of the Polar Urals and the foothills of the Polar Urals, parent materials are represented by colluvium of dense magmatic rocks. In river floodplains, parent material is represented by alluvium (often with high content of gravel material).

Soil diagnostics was carried out according to "Classification and Diagnostics for Russian soils' and 'World reference base for soil resources' (Shishov et al., 2004; World Reference Base For Soil Resources, 2014).

During the fieldwork, investigation of the electrical features of soil and permafrost strata was performed (for the first time for the studied area). Measurements of electrical resistivity of soil and permafrost strata were performed with a portable device Landmapper (to a depth of $300-500 \mathrm{~cm}$ ).

In order to perform more concrete and detailed analysis of electrical resistivity of soils, each key plot must be described separately.

Most of the studied areas are represented by automorphic landscapes on watersheds (excluding the Polar Urals and its foothills sites). However, the vegetation cover is different in the different parts of the studied area.

The surroundings of Salekhard city key plot is represented by drainage landscapes on watersheds with predominance of shrub tundra (Betula nana, Ledum palustre, Empetrum nigrum, Vaccinium uliginosum, Cladonia rangiferina, Sphagnum angustifolium, Sphagnum magellanicum). The soils of this site are characterized by clearly manifested thixotropic features (Fig. 2). It should also be noticed that the widespread presence of hydrolaccolithes within this key plot leads to complications and disturbances in the soil cover in the context of vertical electrical resistivity profiles.

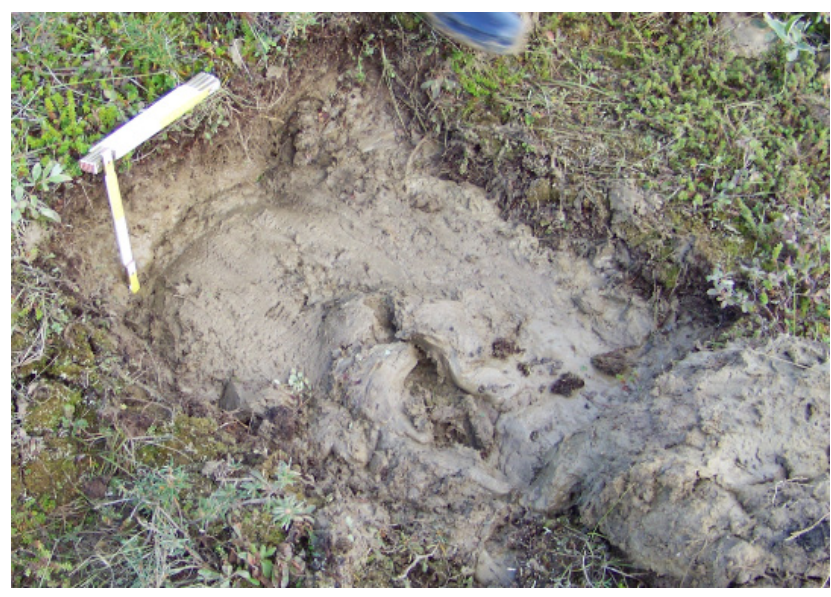

Fig. 2. Thixotropic features clearly manifested in soils (surroundings of Salekhard city key plot, Histic Gleysol).

The Polar Urals (Mountain Chyornaya) key plot is represented mainly by slopes with different steepness and exposure and flat valleys between them. The typical feature for this site is development of sorted circles (patterned ground). They are caused by frost heaving and characterized by high amounts of boulder materials within the soil profiles (Fig. 3). The vegetation cover is represented mainly by shrub tundra associations on the slopes (Ledum palustre, Empetrum nigrum, Vaccinium uliginosum, Cladonia rangiferina) and peat bogs in valleys (Sphagnum angustifolium, Sphagnum magellanicum).

The surroundings of the Khalyatalbey river key plot is characterized by a high influence of alluviation in river valley conditions on soil formation and high occurrence of gravel materials within the soil profiles (Fig. 4). Shrub tundra and forest tundra associations are predominant in the vegetation cover.

The foothills of the Polar Urals key plot is represented mainly by hills with relatively gentle slopes (8-15 degrees). The soils are characterized by high abundance of rocky material (Fig. 4). Automorphic conditions in the upper parts of the slopes are gradually replaced by hydromorphic conditions in the lower parts with decreasing rocky material inclusions and increasing soil profile depth. The vegetation cover is represented mainly by shrub-moss tundra with the presence of trees (Larix sibirica).

Usually, in order to perform vertical electrical resistivity sounding, the so-called Schlumberger geometry is used. The Schlumberger array consists of four collinear electrodes (see the sketch in Fig. 5). The inner two electrodes $(\mathrm{MN})$ are the potential electrodes whereas the outer two (AB) electrodes are current electrodes. The potential electrodes are installed at the centre of the electrode array at small separation. The current electrodes are increased to greater separation during the survey, while the potential electrodes remain in the same position until the observed voltage becomes too small to measure (Keller, 1966; Sharma, 1997). The advantages of this method are that 

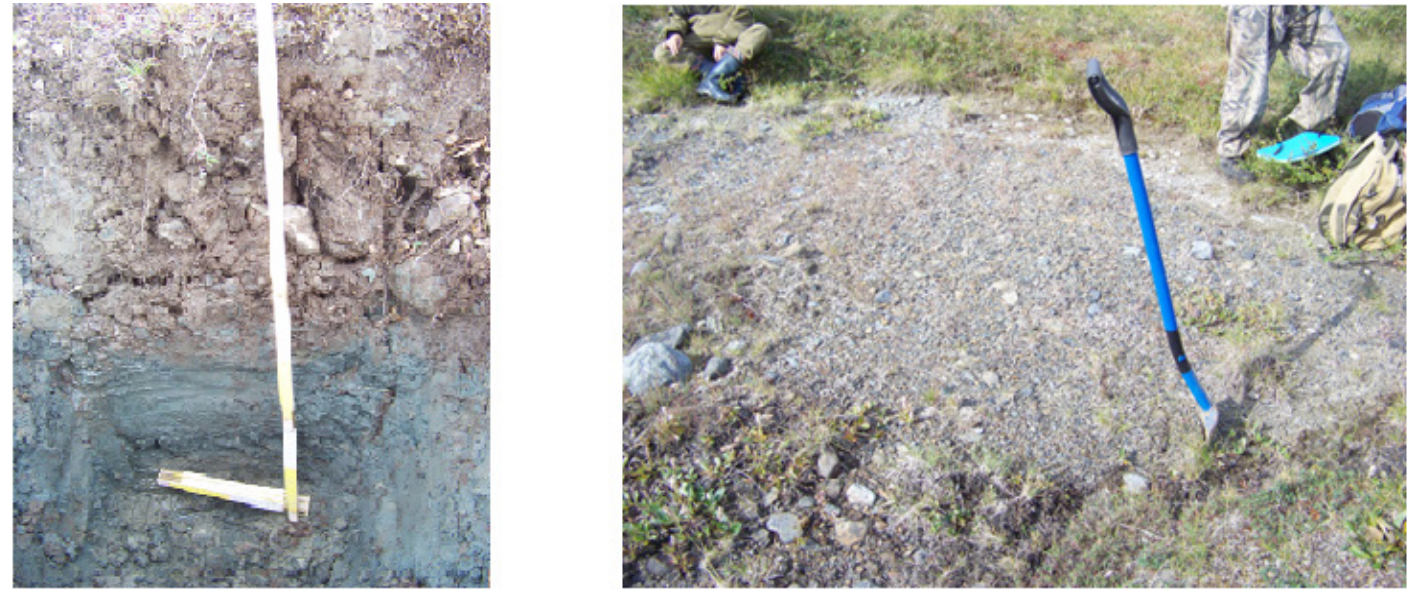

Fig. 3. Sorted circle (patterned ground) and the soil (Gleysol) underlayed by permafrost.

(a)

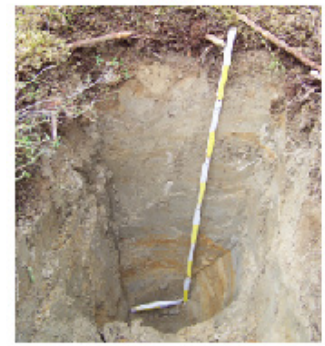

(c)

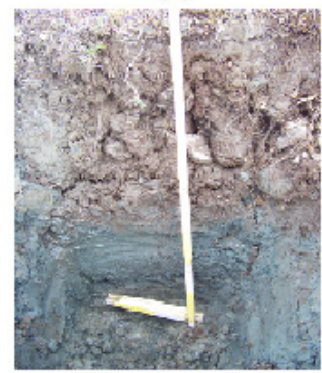

(b)

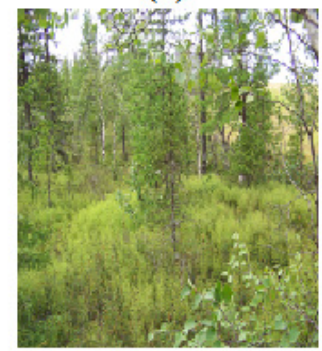

(d)

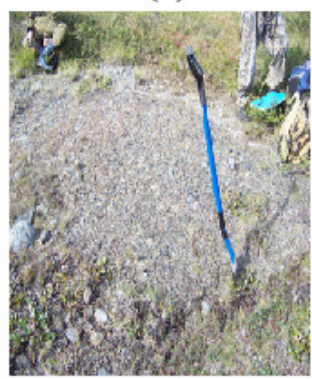

(e)

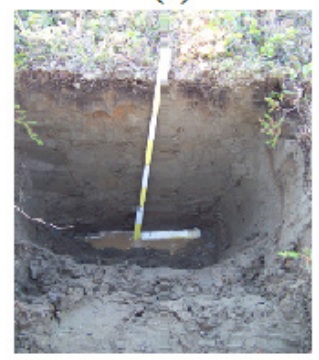

(g)

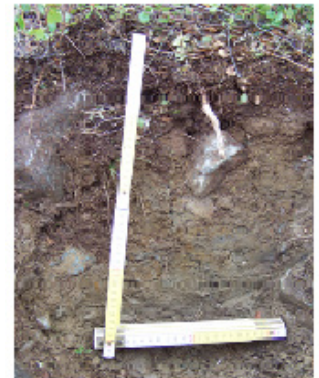

(f)

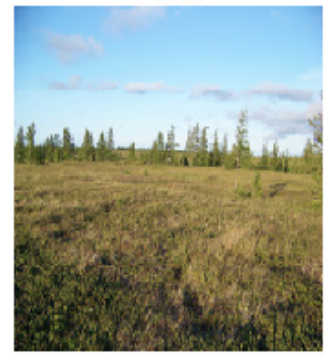

(h)

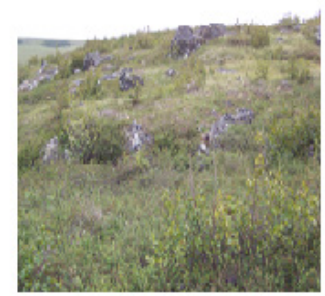

Fig. 4. Examples of soils and landscapes analyzed in this study. Surroundings of Salekhard city (a, b), The Polar Urals (c, d), surroundings of Khalyatalbey river, (e, f), foothills of the Polar Urals ( $g, h)$.

a small number of electrodes need to be moved in order to perform each sounding and the cable length for the potential electrodes is shorter. In comparison with the Wenner array, Schlumberger sounding generally has better resolution, greater probing depth, and less time-consuming field deployment (EPA, 1993).

It must be noticed that the influence of permafrost for the Yamal peninsula seems to be the most important factor affecting electrical resistivity properties in soils. In addition, the processes of cryoturbation and cryogenic mass exchange, which are very widespread in the soils of the Yamal peninsula, result in a complicated picture of profile distribution of electrical resistivity values and serve as prerequisites of their heterogeneity. Moreover, the appearance of the permafrost table changes the profile curves of electrical resistivity $(\mathrm{Ra})$ values, because unfrozen soil is characterized by Ra values of 10-799 $\Omega \mathrm{m}$ and frozen layers are characterized by Ra values of thousands of $\Omega \mathrm{m}$.

A relationship between values of electrical resistivity in soils and predominance of certain category of soil water has been shown (Pozdnyakov et al., 2006). In general, the relationship between the value of electrical resistivity $(E R)$ and water content in the soil $(W)$ can be expressed by the formula:

$$
W=a \exp (-b E R)
$$

where: $a$-parameter that takes into account the effect of the water-holding capacity of the soil on the electrical properties of the soil solution, $b$ - parameter related to the chemical properties of soil and soil solution. The $E R$ of the soil profiles can be estimated from the vertical electrical 


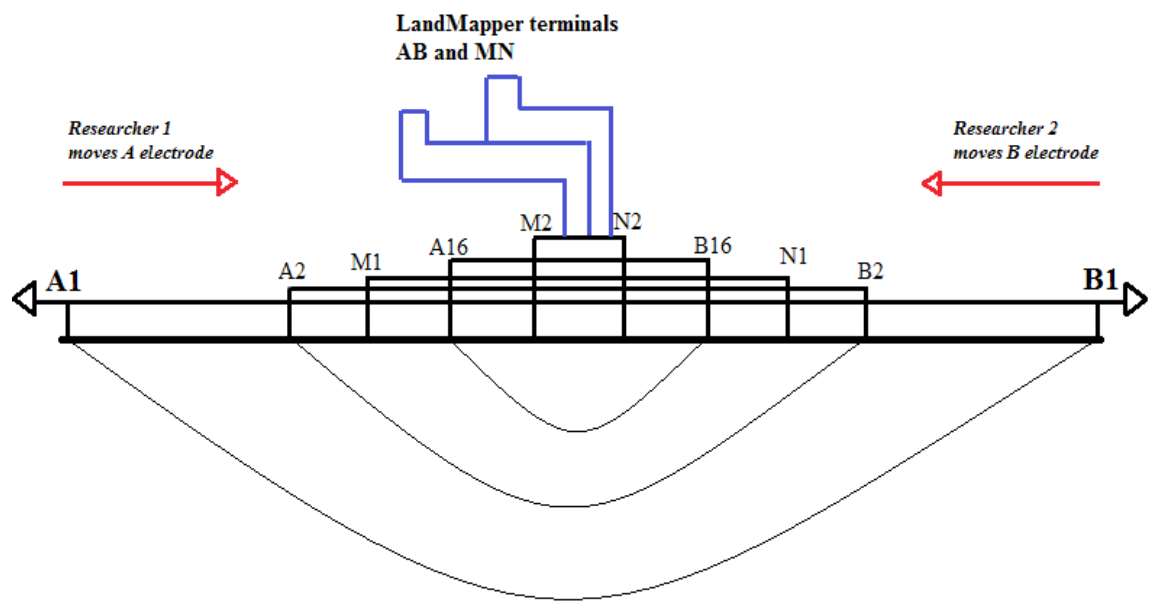

Fig. 5. Sketch illustrated the principle scheme of Schlumberger geometry.

sounding (VERS) measurements, which provides data on the changes in the electrical resistivity throughout the profile from the soil surface without digging pits or drilling. In our study, the resistivity measurements were performed using four-electrode $(\mathrm{AB}+\mathrm{MN})$ arrays of the $\mathrm{AMNB}$ configuration with use of the Schlumberger geometry. A Landmapper ERM-03 instrument (Landviser, USA) was used for the VERS measurements in this study. Vertical electric soundings (VERS) using the Schlumberger configuration were carried out at four locations in different parts of the South Yamal region.

A VERS was used to study the upper 0 to $3 \mathrm{~m}$ thick layer in greater detail. The distance between the A and B electrodes ranged from 10 to $600 \mathrm{~cm}$ while the distance between the $\mathrm{M}$ and $\mathrm{N}$ electrodes was constant $-10 \mathrm{~cm}$. The electrodes were situated on the soil surface with a depth of penetration into soil about $0.5 \mathrm{~cm}$. The geometric factor, $K$, was first calculated for all the electrode spacings using the formula:

$$
K=\pi(\mathrm{L} 2 / 2 \mathrm{~b}-\mathrm{b} / 2),
$$

for the Schlumberger array with $\mathrm{MN}=2 \mathrm{~b}$ and $1 / 2 \mathrm{AB}=\mathrm{L}$. The values obtained were then multiplied with the resistance values to obtain the apparent resistivity. The modelling of the VERS measurements carried out at four stations was used to derive the geo-electric sections for the various profiles. These revealed that there are mostly two or three geologic layers beneath each VERS station. Measurements of the ER were conducted for the first time for soils of the Yamal region during this expedition.

\section{RESULTS AND DISCUSSION}

Data on electric resistivity value changes within the soil profiles are presented in Fig. 6. The general trend of vertical changes in soil resistivity is an increase within the depth. This is typical for permafrost-affected soils and corresponds with data obtained previously for Antarctic soils (Abakumov and Parnikoza, 2015).
The most typical trend in the profile distribution of the Ra values is an increase along the depth with many disturbances (fluctuations), which mainly occur within the soil profile (Fig. 6a). These disturbances are caused by the influence of permafrost inhomogeneity and appearance of the water-saturated layer of soil in contact with the permafrost table (at a depth about $100 \mathrm{~cm}$ ). When the water- saturated layer appears in the soil bottom horizon, electric resistivity decreases (Pozdnyakov, 2008). Fluctuations in Ra values within permafrost strata may be connected with its instability and irregularities. In general, the permafrost table lies at a depth of $160-200 \mathrm{~cm}$.

The profile distribution of Ra values in soils of this key plot is mainly connected with a monotonous increase along the depth (Fig. 6b). In most cases, profile distribution is also characterized by double (or even triple) peaks in Ra values. The typical feature of soils of this key plot is their low thickness, which is caused by superficial bedding of the permafrost table. The soil cover of this key plot has a high level of complexity, which is reflected in differences in the profile distribution of Ra values. In general, the superficial bedding of the permafrost table is very typical (at the depth of 45-60 cm). Low thickness values of the active layer and upper location of the permafrost table are typical for histic soils due to lower temperature conductivity of the histic material (Pastukhov, 2012).

The profile distribution of $\mathrm{Ra}$ values in soils of this key plot is connected with a monotonous increase along the depth (Fig. 6c). However, this monotonous increase is disturbed by fluctuations in Ra values due to cryoturbation processes. The graphs also show that several fluctuations in the $\mathrm{Ra}$ value profile distribution can be observed within the soil profile. The soil-permafrost border is usually distinguished according to the sharp changes in Ra values. In general, the permafrost table lies at a depth of $120-140 \mathrm{~cm}$. The top of this layer is decreasing in electric resistivity, as also shown in the case of the first Polar Ural key plot. 
a
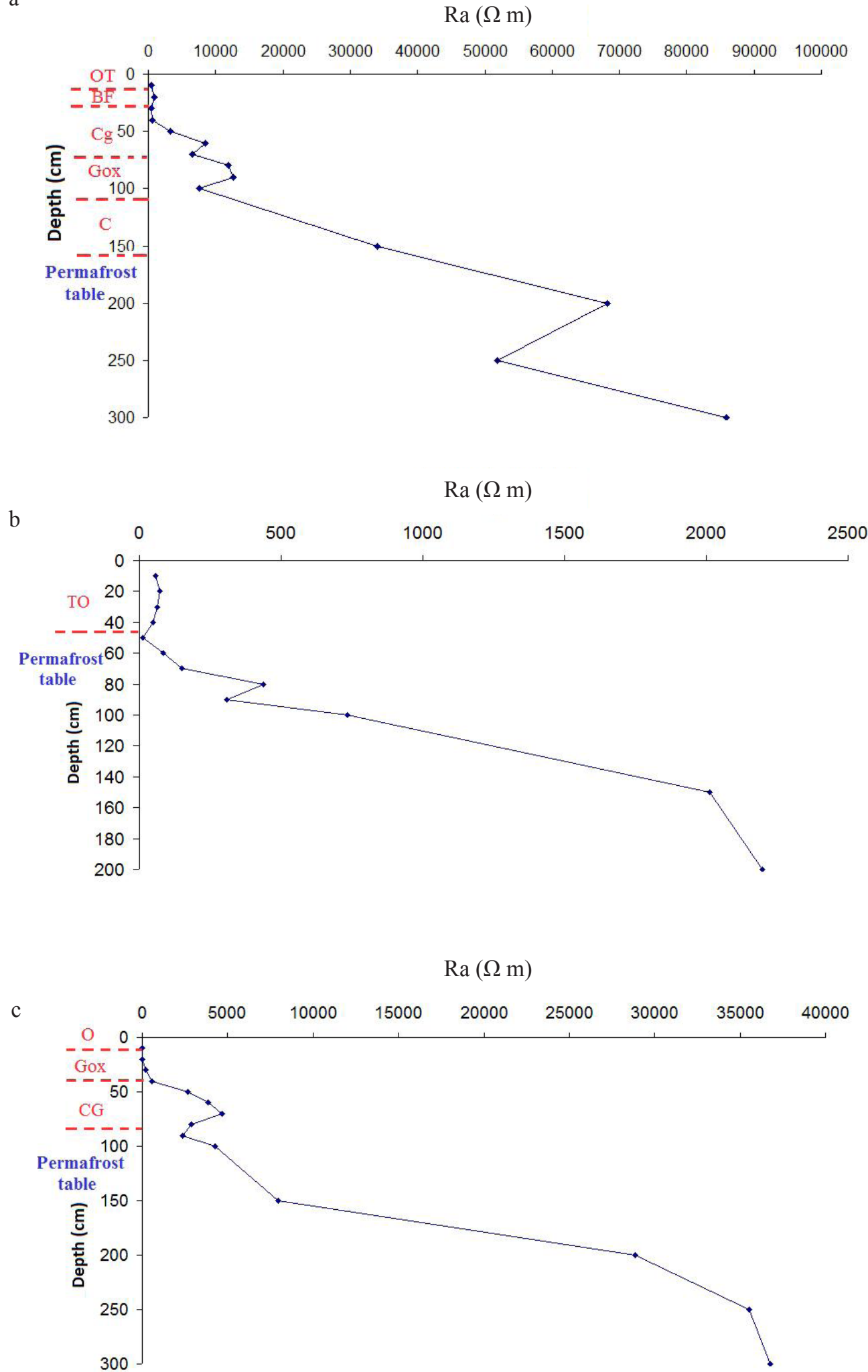

Fig. 6. Typical profile distribution of Ra values in soils of: a - surroundings of Salekhard city, b - Polar Urals, c - surroundings of Khalyatalbey river, and d - Polar Urals key plot. 


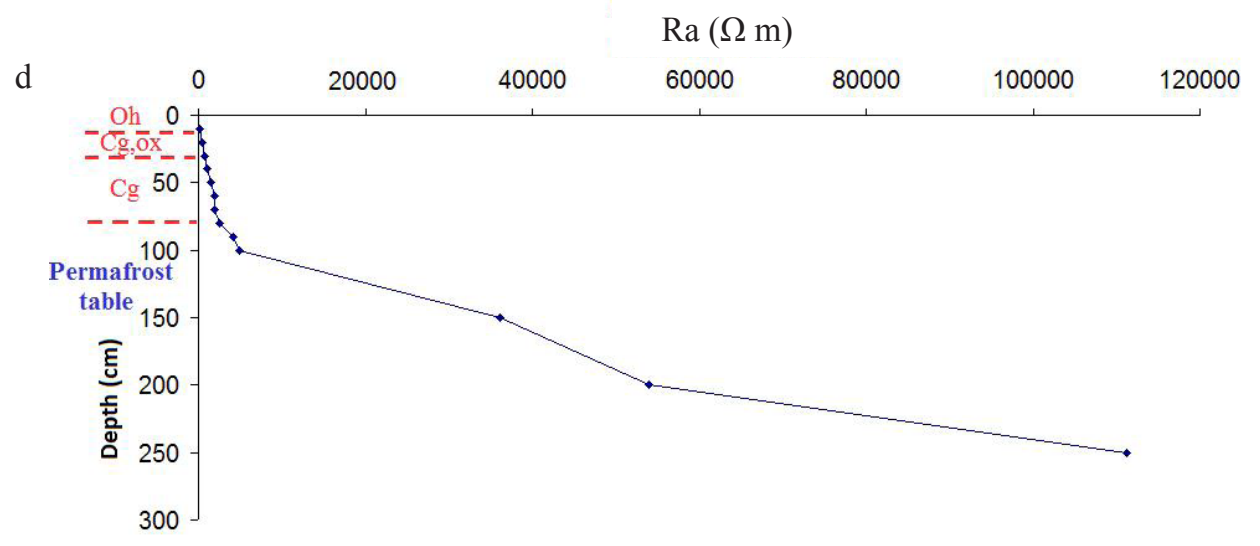

Fig. 6. Continuation.

The typical profile distribution of Ra values in soils of this key plot is mainly connected with a monotonous increase along the depth (Fig. 6d). It may be explained by the inability of soil solutions to penetrate through the cracks down and sealing of the permafrost strata. Unlike the soils of the other key plots, the soils of this key plot show a more or less simple trend of the Ra values profile distribution without disturbances and fluctuations. This type of curve is comparable with those in the soils of the northern part of the Gydan peninsula (Abakumov, 2016) and with the soils of Antarctica (Abakumov and Parnikoza, 2015). It should also be noticed that the electrical resistivity reaches here the highest values, which are more than $100000 \Omega \mathrm{m}$. In general, the permafrost table lies at a depth of $80-120 \mathrm{~cm}$.

\section{CONCLUSIONS}

1. Active layer thickness and soil-permafrost boundary are one of the most important indicators for classification of polar soils. Vertical electrical resistivity sounding performed in the studied area allowed us to determine the heterogeneity of the soil-permafrost strata in terms of electrical resistivity values. It should be emphasised that very sharp changes in electrical resistivity values can usually be observed on the border of different geochemical regimes and pedoenvironments, ie on the active layer-permafrost border.

2. Cryoturbation processes, which are widespread in the studied soils, lead to cryogenic mass transfer, homogenization of soil mass, and complication of the profile distribution of electrical resistivity values.

3. There are several trends in the profile distribution of electrical resistivity values within the permafrost strata. The first trend is connected with a monotonous increase in electrical resistivity values along the depth. This trend may be explained by an increase in electrical resistivity within the soil depth in relation to an increase in permafrost densi- ty. The second trend, in which a sharp decrease is replaced by gradually increasing electrical resistivity values, may be caused by changing of non-frozen friable debris to frozen massive crystalline rock. In general, it has been noticed that the permafrost layer is less homogenous in the upper part of permafrost strata than in the lower part.

4. The vertical electrical resistivity sounding method is quite useful for identification of the permafrost table depth. Vertical electrical resistivity sounding provides significant information on the changes in electrical resistivity values (electrical resistivity values) indirectly (without digging soil pits or drilling activities). This method also allowed us to distinguish genetic horizons within the soil profiles, which have different characteristic electrical resistivity values.

Conflict of interest: The Authors do not declare conflict of interest.

\section{ACKNOWLEDGEMENTS}

This work is devoted to the memory of Dr. Prof. A. Pozdnyakov (Department of Soil Physics, Moscow State University) who was founder of soil electrophysics in Russia and who was passed away 15.08.2015.

\section{REFERENCES}

Abakumov E.V., 2016. Vertical electric sounding of selected Arctic and Antarctic soils: advances in express field investigation of the Cryosols. Geophysical Res. Abstracts, EGU General Assembly, 18, 1, 27-34.

Abakumov E. and Parnikoza I.Yu., 2015. Determination of the soil-permafrost border in selected plots of Antarctic Peninsula on the base of vertical electric sounding data. Ukrainian Antarctic J., 14, 138-142. 
Dymov A.A. and Zhangurov E.V., 2011. Morphological-genetic characterization of soils on the Enganepe Ridge (in Russian). Pochvovedenie, 5, 515-524.

Dymov A.A., Zhangurov E.V., and Startsev V., 2013. Soils of the northern part of the Subpolar Urals: Morphology, physicochemical properties, and carbon and nitrogen pools (in Russian). Pochvovedenie, 8, 507-516.

U.S. EPA, 1993. Subsurface characterization and monitoring techniques: A desk reference guide. Volume 1: Solids and groundwater, EPA/625/R-93/003a. Office of Research and Development, Washington, DC, USA.

Generalov P.P., 1995. Some peculiarities of tectonics and geomorphology (in Russian). Nature of Yamal, Nauka.

Goryachkin S.V., 2010. Soil cover of the north. In: Patterns, Genesis, Ecology, Evolution (in Russian). Publishing House GEOS, Moscow, Russia.

Hauck C. and Vonder Mühll D., 1999. Using DC resistivity tomography to detect and characterise mountain permafrost. Proc. 61. Europ. Association of Geoscientists and Engineers (EAGE) Conf., June 7-11, Helsinki, Finland.

Hoekstra P. and McNeill D., 1973. Electromagnetic probing of permafrost. In: The North American Contribution to the 2nd Int. Conf. Permafrost. National Research Council, National Academy of Sciences, Washington, DC, USA.

Hoekstra P., Sellmann P., and Delaney A., 1975. Ground and airborne resistivity surveys of permafrost near Fairbanks, Alaska. Geophysics, 40, 641-656.

Ivanov I., Alexandrovskiy A.L., Makeev O.A., Bulgakov D.S., Abakumov E.V., et al., 2015. Evolution of soil and soil cover. Theory and diversity of natural evolution and anthropogenic soil transformation (in Russian). Moscow, GEOS, Moscow, Russia.

Iwata S., Tabuchi T., and Warkentin B.P., 1995. Soil-water interactions. Mechanisms and applications. Marcel Dekker, Inc. 270 Madison Avenue, New York, NY 10016, USA.

Keller G.V., 1966. In Handbook of Physical Constants, pp. 553577, Geol. Soc. Am. Memoir 97, Washington, DC, USA.

Keller G.V. and Frischknecht F.C., 1966. Electrical Methods in Geophysical Prospecting. Pergamon Press, New York, USA.

Kemper W.D., Olsen J., and DeMooy C.J., 1975. Dissolution rate of gypsum in flowing water. Soil Sci. Soc. Am. Proc., 39, 458-463.

King M.S., Zimmerman R.W., and Corwin R.F., 1988. Seismic and electrical properties of unconsolidated permafrost. Geophysical Prospecting, 36, 349-364.

Magnin F., Krautblatter M., Deline P., Ravanel L., Malet E., and Bevington A., 2015. Determination of warm, sensitive permafrost areas in near-vertical rockwalls and evaluation of distributed models by electrical resistivity tomography. J. Geophysical Res., 120(5), 745-762.

Mil'kov F.N. and Gvozdecky N.A., 1986. Physical geography of USSR. Overview. European part of USSR. Caucasus (in Russian). Vyshshaya Shkola, Moscow, USSR.

Olhoeft G.R., 1978. Electrical properties of permafrost: Proc. 3rd Int. Conf. On Permafrost. Nat. Res. Counc., Edmonton, Canada.

Pastukhov A.V., 2012. Micromophological structure of permafrost-affected and seasonally long-term frrezing soils of the European North-East. Izvestia Komi of scientific centre URO RAN, 4, 30-39.

Pozdnyakov A.I., 2008. Electrical soil parameters and soil formation process (in Russian). Pochvovedenie, 10, 1188-1197.

Pozdnyakov A.I., Pozdnyakova L.A., and Karpachevskii L.O., 2006. Relationship between Water Tension and Electrical Resistivity in Soils. Eurasian Soil Sci., 39, Suppl. 1, 78-83.

Samouëlian A., Cousin I., Tabbagh A., Bruand A., and Richard G., 2005. Electrical resistivity survey in soil science: a review. Soil Tillage Res., 83, 173-193.

Scott W.J. and Kay A.E., 1988. Earth resistivities of Canadian soils: Can. Elect. Assoc., Montreal. Vol. 1, Main Rep., Vol. 2., Site data.

Scott W.J., Sellmann P.V., and Hunter J.A., 1990. Geophysics in the study of permafrost. In: Geotechnical and Environmental Geophysics (Ed. S.H. Ward). Investigations in Geophysics, Review and Tutorial, Society of Exploration Geophysicists, Tulsa, 1(5), 355-384.

Sharma P.V., 1997. Environmental and Engineering Geophysics. Cambridge University Press, Cambridge, MA, USA.

Shishov L.L., Tonkonogov V.D., and Lebedeva I.I., 2004. Classification and diagnostics for Russian soils (in Russian). Oykumena, Smolensk, Russia.

Smernikov S.A., Pozdnyakov A.I., and Shein E.V., 2008. Assessment of Soil Flooding in Cities by Electrophysical Methods. Eurasian Soil Sci., 41, 1059-1065.

Sudha K., Israil M., Mittal S., and Rai J., 2008. Soil characterization using electrical resistivity tomography and geotechnical investigations. J. Applied Geophysics, 67, 74-79.

Tarnocai C., Canadell J., Schuur E., Kuhry P., Mazhitova G., and Zimov S., 2009. Soil organic carbon pools in the northern circumpolar permafrost region. Global Biogeochemical cycles, 23, 1-11.

Vasil'evskaya V.D., 1980. Soil formation in the Western Siberian tundras (in Russian). Nauka, Moscow, USSR.

World Reference Base For Soil Resources. FAO. 2014. 